This item was submitted to Loughborough's Research Repository by the author.

Items in Figshare are protected by copyright, with all rights reserved, unless otherwise indicated.

\title{
Thermoelastohydrodynamics of grease-lubricated concentrated point
} contacts

PLEASE CITE THE PUBLISHED VERSION

PUBLISHER

Professional Engineering Publishing / @ IMechE

VERSION

VoR (Version of Record)

LICENCE

CC BY-NC-ND 4.0

\section{REPOSITORY RECORD}

Karthikeyan, B.K., M. Teodorescu, Homer Rahnejat, and Steve Rothberg. 2019. "Thermoelastohydrodynamics of Grease-lubricated Concentrated Point Contacts". figshare. https://hdl.handle.net/2134/6123. 
This item was submitted to Loughborough's Institutional Repository (https://dspace.lboro.ac.uk/) by the author and is made available under the following Creative Commons Licence conditions.

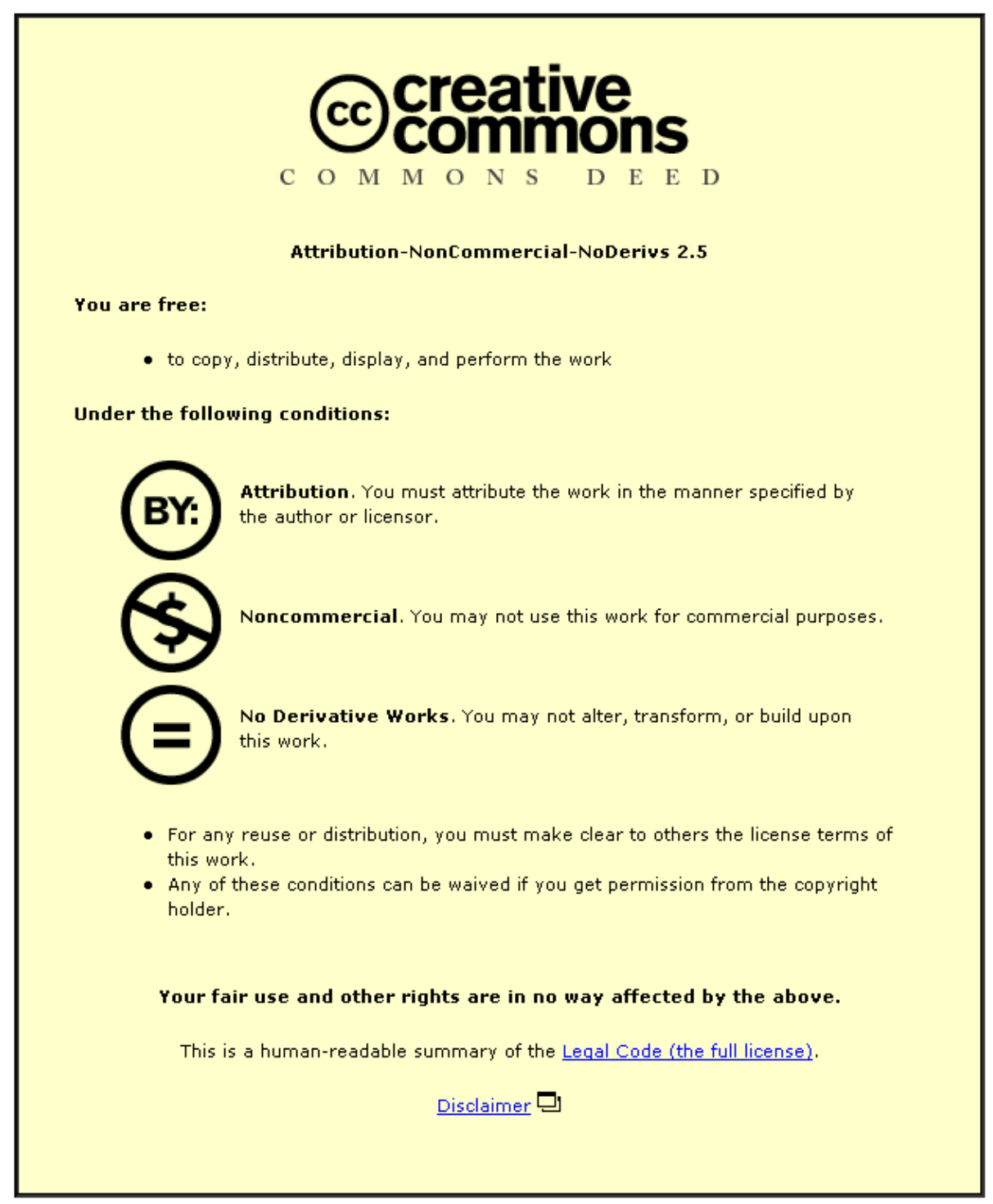

For the full text of this licence, please go to: http://creativecommons.org/licenses/by-nc-nd/2.5/ 


\title{
Thermoelastohydrodynamics of grease-lubricated concentrated point contacts
}

\author{
B K Karthikeyan ${ }^{1}$, M Teodorescu ${ }^{2}$, H Rahnejat ${ }^{1 *}$, and S J Rothberg ${ }^{1}$ \\ ${ }^{1}$ Wolfson School of Mechanical and Manufacturing Engineering, Loughborough University, Loughborough, UK \\ ${ }^{2}$ Department of Automotive Engineering, Cranfield University, Cranfield, UK
}

The manuscript was received on 29 May 2009 and was accepted after revision for publication on 16 September 2009.

DOI: 10.1243/09544062JMES1748

\begin{abstract}
Isothermal and thermoelastohydrodynamic lubrication (TEHL) analyses of grease lubricated bearings are presented. A grease plug flow is formed in the conjunction that, with no shear at the boundaries with the solid surfaces, adheres to them in the region of high pressures under isothermal conditions. The elastohydrodynamic lubrication grease pressure distribution conforms fairly closely to that of its base oil alone, with the exception of inlet trail and pressure spike regions. The dependency of film thickness on speed (rolling viscosity) and load parameters for the base oil agrees with previously reported findings of the research community. For grease there are subtle differences with the base oil film thickness load and speed dependencies. However, it is clear that extrapolated oil film thickness formulae for oils can be used reasonably for the prediction of grease films, at least as a first approximation. The results presented agree well with optical interferometric measurements reported in the literature for grease-lubricated contacts at low temperatures and low surface velocities. TEHL analysis shows breakdown of the plug flow and significant reduction in film thickness, which can lead to changes in the regime of lubrication to mixed or boundary conditions.
\end{abstract}

Keywords: grease lubrication, thermoelastohydrodynamics, Herschel-Bulkley model, Bingham pseudo-plastic behaviour, grease plug flow

\section{INTRODUCTION}

The convenience, effectiveness, low cost, and simplicity of grease have meant that it has been one of the most frequently employed lubrication methods for ball and rolling element bearings. Greases, in general, behave as shear-thinning or pseudo-plastic fluids. Thus, their viscosity reduces under shear. With sufficient shear, the viscosity of grease approaches that of the base lubricant. This behaviour means that grease may be considered as a plastic fluid. Any reduction in shear with time makes the behaviour thixotropic. Modern, specially formulated greases are able to sustain entraining speeds of up to 2.4 million DN at fairly high temperatures. Although higher speeds can be achieved with recirculating oil-lubricated bearings,

\footnotetext{
${ }^{*}$ Corresponding author: Wolfson School of Mechanical and Manufacturing Engineering, Loughborough University, Loughborough, Leicestershire LE11 3TU, UK.

email:h.rahnejat@lboro.ac.uk
}

grease-packed bearings have almost revolutionized the high-speed precision spindles used in some machine tools such as routers.

Rolling elements-to-races contacts are subject to the elastohydrodynamic regime of lubrication (EHL) during most of their service life. The EHL theory is now well established for oil-lubricated contacts, particularly under isothermal conditions [1-3]. However, much less research has been devoted to the case of grease EHL, even though nearly 85 per cent of industrial bearings operate with grease-packed bearings.

Optical interferometric studies of grease-lubricated contacts have shown that the grease film thickness under nominally fully flooded conditions is always thicker than that of the base oil $[\mathbf{4}, \mathbf{5}]$. Other studies $[6,7]$ on grease composition have shown that the film thickness increases with higher base oil viscosity and soap concentration in the grease. Fully sheardegraded grease behaves as discrete spherical soap particles, dispersed in the base oil through its passage in the contact inlet region [8]. Larsson et al. [9] 
note that the usual solutions for grease EHL based on the base oil may not suffice when soap lumps enter the contact domain. They suggest that calculations should be based on measured films, from which the corresponding pressure distributions may be obtained.

Experiments have revealed that the measured grease EHL film thickness is initially greater than it would be if its base oil content were acting alone [10]. With continued running, however, the film thickness due to grease declines to about 60 per cent of its base oil. The initial thick grease layer is rapidly removed by the rolling or sliding motion, and lubrication is controlled by a thin viscous layer that is a mixture of oil and degraded thickener [11]. The decline in the film thickness can only be explained, in general terms, as being related to the scarcity of grease in the contact. However, before now there has been no detailed work conducted to test this hypothesis because of the complexity of grease rheological behaviour.

Grease rheological properties are dependent on both the shear rate and the duration of shearing action [12]. At low shear rates, grease behaves as a plastic solid and does not flow until a critical yield stress is reached. This type of fluid is generally regarded as a HerschelBulkley [13] or Bingham [14] plastic fluid. A plug flow is usually encountered, as verified experimentally [15]. The Herschel-Bulkley fluids are described by a threeparameter rheological model. Once the yield stress is exceeded, a Herschel-Bulkley fluid flows with a nonlinear constitutive (stress-strain) relationship either as a shear-thickening fluid or as a shear-thinning one. Numerical analysis using the Herschel-Bulkley model by Kauzlarich and Greenwood [16] has shown that most greases behave pseudo-plastically. Although the shear stress for a given shear rate does not fall below the shear stress of the corresponding base oil at the same temperature, it may be possible to have a smaller film thickness than that of the base oil alone because of thermal fluid flow of grease at the conjunctional inlet. Numerical solutions by Jonkisz and KrzeminskiFreda [17] have confirmed the postulate that values calculated using EHL extrapolated film thickness formulae for the base oil are a good approximation of the grease film thickness as well. The pressure distribution generated by grease has also shown a peak pressure closer to the centre of the high-pressure area than that for oil under the same operating conditions. A significant feature that differentiates the flow of grease from oil is the existence of a plug flow. Jonkisz and Krzeminski-Freda [17] found that the plug in the highpressure zone was present throughout the duct. Film thickness comparison for fresh grease and sheared (partially degraded) grease with its base oil was carried out by Cheng [18]. A comparison was also made for the film thickness when the Bingham and the HerschelBulkley models were assumed. The predictions were found to be in agreement at low entraining velocities, which diverged at medium velocities.

Yoo and Kim [19] studied the effect of temperature and rheology on the grease film thickness using the Herschel-Bulkley model. For this model all the studies reported are limited to the line contact configuration and at low-to-medium entraining velocities. The numerical solution of the modified Reynolds equation for grease for point contacts remains challenging despite the advent of powerful computational techniques and platforms. Isothermal and thermal analyses of grease-lubricated concentrated point contacts are shown in this article. The formulations reported here are generic.

\section{THEORETICAL FORMULATION}

\subsection{The modified Reynolds equation for grease flow}

For grease lubrication, a modified form of Reynolds equation should be derived to take into account the flow behaviour of pseudo-plastics and the resulting plug formation and flow. The direction of entraining motion is assumed to coincide with the $x$ coordinate, while the $z$-coordinate remains normal to the bounding contacting surfaces with the origin of the coordinate centre being coincident with the centre of the oil film (see Fig. 1). Thus, the $y$-direction represents the side leakage. As in the usual Reynolds assumption, inertial and body forces are neglected. The shear stress $\tau$ is considered to be a function of the $z$-direction variations only, meaning that the oil film is nearly parallel. The shear stress and plastic viscosity only alter with pressure and in the $x$ - and $y$-directions. Thus, the force balance on an element of fluid yields

$$
\frac{\partial \tau_{z x}}{\partial z}=\frac{\partial p}{\partial x}
$$

and

$$
\frac{\partial \tau_{z y}}{\partial z}=\frac{\partial p}{\partial y}
$$

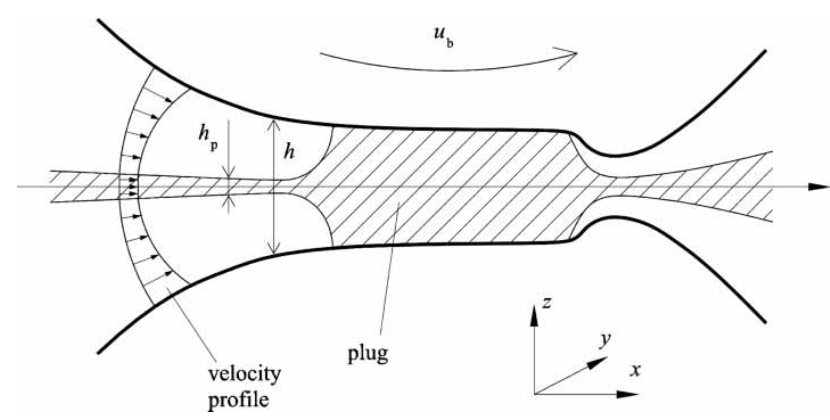

Fig. 1 Film profile and plug flow 
If pressure variation across the thin film is ignored, then integrating the above equations gives

$$
\tau_{z x}=z \frac{\partial p}{\partial x}
$$

and

$$
\tau_{z y}=z \frac{\partial p}{\partial y}
$$

The Herschel-Bulkley equation is one of the more realistic constitutive models for grease, described by a three-parameter rheological model as [13]

$$
\tau=\tau_{0}+\phi|D|^{n}
$$

When the local shear stress is below the yield stress $\tau_{0}$, the Herschel-Bulkley fluids are deemed to behave as rigid solids. Once the yield stress is exceeded, however, the Herschel-Bulkley fluids flow according to a non-linear constitutive relationship, either as a shearthickening fluid or as a shear-thinning one. According to the model a central flow region occurs in which $\tau<\tau_{0}$, which is enclosed by regions of shear flow (if $\tau>\tau_{0}$ ).

If the plug flow region is of thickness $h_{\mathrm{p}}$ as shown in Fig. 1, then

$$
\begin{aligned}
\tau_{z x} & =\frac{h_{\mathrm{p}}}{2} \frac{\partial p}{\partial x} \\
\tau_{z y} & =\frac{h_{\mathrm{p}}}{2} \frac{\partial p}{\partial y}
\end{aligned}
$$

Rearranging the Herschel-Bulkley equation (5) gives

$$
\phi\left(\frac{\mathrm{d} u}{\mathrm{~d} z}\right)^{n}=\left(z-\frac{h_{\mathrm{p}}}{2}\right) \frac{\partial p}{\partial x}
$$

and substituting for $(1 / n)=m$ and $(\partial p / \partial x)=\left(2 \tau_{0} / h_{\mathrm{p}}\right)$ gives

$$
\frac{\mathrm{d} u}{\mathrm{~d} z}=\left(z-\frac{h_{\mathrm{p}}}{2}\right)^{m}\left(\frac{2 \tau_{0}}{\phi h_{\mathrm{p}}}\right)^{m}
$$

Since pressure, and therefore the yield stress and plastic viscosity, are assumed to be a function of the $x$ - and $y$-coordinates only, these equations can be integrated directly to yield the velocity gradients

$$
\begin{aligned}
u= & u_{\mathrm{b}}+\left(\frac{2 \tau_{0}}{\phi h_{\mathrm{p}}}\right)^{m} \frac{1}{(m+1)} \\
& \times\left[\left(z-\frac{h_{\mathrm{p}}}{2}\right)^{m+1}-\left(\frac{h}{2}-\frac{h_{\mathrm{p}}}{2}\right)^{m+1}\right]
\end{aligned}
$$

where for plug flow

$$
z=\frac{h_{\mathrm{p}}}{2}
$$

It is convenient and reasonable to consider grease as a Bingham fluid; thus $m=n=1$. The flow for a Bingham plastic was explained by Bingham [14] in 1922 as follows: the lubricant solidifies if the applied shear is less than its yield stress. This happens at the centre of the contact, where a plug flow is considered. The plug core height $h_{\mathrm{p}}$ would be very small. In such a case it is considered that the core formed due to the stress level below the yield stress would float. The second case is when the pressure reaches its maximum value at the centre of the contact, where there is no shear and the lubricant would solidify and adhere to the surfaces. This case occurs only at the contact centre and in the region of the minimum exit film, as noted by Wada et al. [20] for the Bingham model. Therefore, the core velocity becomes

$$
u_{\mathrm{p}}=u_{\mathrm{b}}-\left(\frac{\tau_{0}}{\phi h_{\mathrm{p}}}\right) \frac{1}{4}\left(h-h_{\mathrm{p}}\right)^{2}
$$

The flow can be considered as the sum of the plug flow and the flow of the base oil itself; thus the volume flow per unit width is the sum of the volume of plug flow and the volume of the upper shear flow region. Assuming a symmetrical flow field between the bounding surfaces, the volume flow per unit width can be obtained as

$$
q_{x}=2 \int_{0}^{h / 2} u \mathrm{~d} z=2\left(\int_{0}^{h_{\mathrm{p}} / 2} u \mathrm{~d} z+\int_{h_{\mathrm{p}} / 2}^{h / 2} u \mathrm{~d} z\right)
$$

After integration, using the above boundary conditions, the volumetric flow in the entraining flow becomes

$$
q_{x}=u_{\mathrm{b}} h+h_{\mathrm{p}}\left(u_{\mathrm{p}}-u_{\mathrm{b}}\right)-\frac{\partial p}{\partial x} \frac{\left(h-h_{\mathrm{p}}\right)^{3}}{12 \phi}
$$

and in side leakage

$$
q_{y}=v_{\mathrm{b}} h+h_{\mathrm{p}}\left(v_{\mathrm{p}}-v_{\mathrm{b}}\right)-\frac{\partial p}{\partial x} \frac{\left(h-h_{\mathrm{p}}\right)^{3}}{12 \phi}
$$

Now, using the continuity of flow condition

$$
\begin{aligned}
& h \frac{\partial \rho}{\partial t}+\frac{\partial}{\partial x}(v)-\rho u_{\mathrm{p}} \frac{\partial h}{\partial x}+\frac{\partial}{\partial y}\left(\rho q_{y}\right)-\rho v_{\mathrm{p}} \frac{\partial h}{\partial y} \\
& \quad+\rho\left(w_{\mathrm{a}}-w_{\mathrm{p}}\right)=0
\end{aligned}
$$

the Reynolds equation is obtained as

$$
\begin{aligned}
& \frac{\partial}{\partial x}\left(\frac{\rho h_{\mathrm{a}}^{3}}{\phi} \frac{\partial p}{\partial x}\right)+\frac{\partial}{\partial y}\left(\frac{\rho h_{\mathrm{a}}^{3}}{\phi} \frac{\partial p}{\partial y}\right) \\
& \quad=12\left[\frac{\partial}{\partial x} \rho\left(u_{\mathrm{b}} h-u h_{\mathrm{p}}\right)+\frac{\partial}{\partial y} \rho\left(v_{\mathrm{b}} h-v h_{\mathrm{p}}\right)+\frac{\partial(h \rho)}{\partial t}\right]
\end{aligned}
$$

where $u=\left(u_{\mathrm{b}}-u_{\mathrm{p}}\right), v=\left(\nu_{\mathrm{b}}-v_{\mathrm{p}}\right)$, and $h_{\mathrm{a}}=\left(h-h_{\mathrm{p}}\right)$. 
Assuming no side leakage, the equation can be simplified to (used in the current analysis)

$$
\begin{aligned}
& \frac{\partial}{\partial x}\left(\frac{\rho h_{\mathrm{a}}^{3}}{\phi} \frac{\partial p}{\partial x}\right)+\frac{\partial}{\partial y}\left(\frac{\rho h_{\mathrm{a}}^{3}}{\phi} \frac{\partial p}{\partial y}\right) \\
& \quad=12\left[\frac{\partial}{\partial x} \rho\left(u_{\mathrm{b}} h-u h_{\mathrm{p}}\right)+\frac{\partial(h \rho)}{\partial t}\right]
\end{aligned}
$$

For oil-lubricated contacts with no core formation and plug flow: $h_{\mathrm{p}}=0$, and the plug flow velocities are equal to that of the base oil; thus $u_{\mathrm{p}}=u_{\mathrm{b}}$ and $v_{\mathrm{p}}=v_{\mathrm{b}}$. This yields the usual Reynolds equation.

\subsection{Energy equation}

In practice, shearing of the lubricant in contact as well as the pressure gradient due to the wedge effect lead to heat generation, which influences lubricant rheology and thus the film thickness. Therefore, in order to obtain realistic predictions, thermal effects should also be considered. This is achieved by the simultaneous solution of the Reynolds and energy equations.

Heat is removed from the contact by a combination of convection (due to lubricant entrainment and side leakage) and conduction through the bounding solids (the right-hand side of the energy equation)

$$
\begin{gathered}
\rho \theta v\left(u \frac{\partial p}{\partial x}+v \frac{\partial p}{\partial y}\right)+\phi\left(\frac{\partial u}{\partial z}\right)^{2} \\
=\rho C_{\mathrm{p}}\left(u \frac{\partial \theta}{\partial x}+v \frac{\partial \theta}{\partial y}\right)-k \frac{\partial^{2} \theta}{\partial z^{2}}
\end{gathered}
$$

Cameron [2] and Gohar and Rahnejat [3] have shown that convective heat transfer is small compared with conduction through the contacting surfaces in thin elastohydrodynamic films. This is particularly true in the case of grease lubrication, as the base oil becomes trapped inside the soap fibres of grease. Thus, the first term on the right-hand side of the energy equation may be neglected. Furthermore, the side leakage is considered to be insignificant in the current analysis. Thus, the energy equation simplifies to

$$
u \theta \alpha^{\prime} \frac{\partial p}{\partial x}+\phi\left(\frac{\partial u}{\partial z}\right)^{2}=-k \frac{\partial^{2} \theta}{\partial z^{2}}
$$

Using the analytical approach proposed in references [2] and [3], the temperature gradient across the film is assumed to vary linearly as $\Delta \theta / h$. This gives a parabolic temperature distribution across the film; thus the heat taken away by conduction (the right-hand side of equation (19)) at the top surface throughout the contact becomes the following [3]: $b k \Delta \theta / h$. The analytical approach also assumes the principle of superposition of contributions on the lefthand side of equation (19). For viscous heating, one may assume linear velocity variation across the film and integrating $\phi \int_{-b}^{b} \int_{0}^{h}(\partial u / \partial z)^{2} \mathrm{~d} z \mathrm{~d} x=\left(2 \phi u^{2} b / h\right)$. For compressive heating, for the entire contact, $\int_{-b}^{b} \int_{0}^{h} u \theta \alpha^{\prime}(\partial p / \partial x) \mathrm{d} z \mathrm{~d} x=u\left(\theta_{i}+\Delta \theta\right) \alpha^{\prime} h p_{\max }$. Therefore, a simplified analytical solution to the energy equation is obtained, yielding the temperature rise as

$$
\Delta \theta=\left[\frac{u \theta_{i} \alpha^{\prime} h p_{\max }+\left(2 b \phi u^{2} / h\right)}{(b k / h)-u \alpha^{\prime} h p_{\max }}\right]
$$

\subsection{Lubricant rheology}

The density and viscosity of lubricant, particularly the latter, vary with pressure and temperature. The density dependence on pressure and temperature follows the usual relationship given by Dowson and Higginson [1]

$$
\rho=\rho_{0}\left[\left(1+\frac{0.6 \times 10^{-9} p}{1+1.7 \times 10^{-9} p}\right)-D_{t}\left(\theta-\theta_{i}\right)\right]
$$

The viscosity of the lubricant is quite sensitive to changes in both pressure and temperature. For medium to high pressures experienced in elastohydrodynamic contacts, the relationship proposed by Roelands [21] or Houpert [22] is appropriate

$$
\begin{aligned}
\phi=\phi_{0} \exp \left\{( \operatorname { l n } \phi _ { 0 } + 9 . 6 7 ) \left[-1+\left(1+5.1 \times 10^{-9} p\right)^{z^{\prime}}\right.\right. \\
\left.\left.\times\left(\frac{\Theta-138}{\Theta_{i}-138}\right)^{-S_{0}}\right]\right\}
\end{aligned}
$$

where the contact temperature $\Theta=\theta_{i}+\Delta \theta+273$ is in Kelvin. $S_{0}$ is a constant calculated as

$$
S_{0}=\beta\left(\frac{\Theta_{i}-138}{\ln \phi_{0}+9.67}\right)
$$

and

$$
z^{\prime}=\frac{\alpha}{5.1 \times 10^{-9}\left(\ln \eta_{0}+9.67\right)}
$$

When grease is used as the lubricant in high-speed precision applications, its use is often limited by speed due to viscous friction and lack of convection cooling. Thus, to achieve the highest possible speeds, greases with a synthetic base oil (diester) combined with a barium complex soap are used. These have good temperature stability and are non-toxic.

In general, grease is assumed to be fully sheardegraded by its passage through the contact inlet when its structure becomes a large-scale three-dimensional (3D) network of discrete spherical soap particles, dispersed in the base oil [23]. In this case, the viscosity of the grease would conform to

$$
\phi=\eta(1+B \Phi)
$$

where $\phi$ is the plastic viscosity of grease, $\eta_{\text {bo }}$ is the base oil viscosity, $B \approx 0.25$ is a constant, and $\Phi$ is the volume fraction of soap in oil (see Appendix 2). 


\subsection{Thickness of the plug}

To find a solution, the thickness of the grease plug must be determined at any position $x, y$ in the conjunction. Considering grease as a Bingham fluid, the components of strain rate tensor $\dot{\varepsilon}_{i, j}$ can be written as

$$
\begin{array}{ll}
\dot{\varepsilon}_{i, j}=\frac{1}{\eta} \frac{\sqrt{I_{2}}-\tau_{0}}{\sqrt{I_{2}}} \sigma_{i, j} & \text { for } \sqrt{I_{2}} \geqslant \tau_{0} \\
\dot{\varepsilon}_{i, j}=0 & \text { for } \sqrt{I_{2}} \leqslant \tau_{0}
\end{array}
$$

where $\sigma_{i, j}$ is the deviatoric component of the stress tensor and $I_{2}$ is the second invariant of the deviatoric stress, where

$$
I_{2}=\tau_{z x}^{2}+\tau_{z y}^{2}=\tau^{2}
$$

For the plug flow region of thickness $h_{\mathrm{p}}$ and $\tau=\tau_{0}$, substituting equations (6) and (7) into equation (27) and rearranging gives

$$
h_{\mathrm{p}}=\frac{2 \tau_{0}}{\sqrt{\left[(\partial p / \partial x)^{2}+(\partial p / \partial y)^{2}\right]}}
$$

\subsection{Elastic film shape}

The elastohydrodynamic film shape is given by the approximate parabolic shape of the contact of an ellipsoidal solid near a flat semi-infinite elastic half-space subjected to a localized Hertzian deformation. With an initial gap of $h_{0}$, the elastic film shape for a spherical solid such as a ball bearing is $[\mathbf{1}-\mathbf{3}, \mathbf{2 4}]$

$$
h(x, y)=h_{0}+\frac{x^{2}}{2 R_{x}}+\frac{y^{2}}{2 R_{y}}+\delta(x, y)
$$

$\delta(x, y)$ is the local deformation and is obtained through a solution of the generalized potential elasticity integral

$$
\delta(x, y)=\frac{2}{\pi E^{\prime}} \int_{-a}^{a} \int_{-b}^{b} \frac{p\left(x_{1}, y_{1}\right) \mathrm{d} x_{1} \mathrm{~d} y_{1}}{\left[\left(y-y_{1}\right)^{2}+\left(x-x_{1}\right)^{2}\right]^{1 / 2}}
$$

In an $n_{x} \times n_{y}$ computational grid, the above equation can be solved analytically for the combined effect of pressure elements $p_{i, j}$ contributing to deflection at a point $k, l$. This yields a set of influence coefficients that enable the evaluation of contact deflection by the superposition principle as

$$
\delta_{k, l}=\frac{2}{\pi E^{\prime}} \sum_{j=1}^{n x} \sum_{i=1}^{n y} p_{i, j} D_{m, n}
$$

where $m$ and $n$ incorporate within them the effect of a pressure node $(i, j)$ on a deflection node $(k, l)$ and are expressed as [25, 26]: $m=|k-i|$ and $n=|l-j|$ (see Appendix 3).

\subsection{Boundary and initial conditions}

For a numerical solution, boundary and initial conditions are required. Pressure at the boundaries of the computation domain is assumed to be zero. These boundaries are initially set far from the edge of the Hertzian elastostatic contact footprint, generally five times the Hertzian radius upstream of the contact and 1.5 times along each side boundary [3]. Thus

$$
p_{i, 1}=p_{i, N+1}=p_{1, j}=p_{M+1, j}=0
$$

At the exit boundary in the direction of entraining motion, the lubricant film ruptures, beyond which cavitation occurs. The Reynolds or Swift-Steiber exit boundary condition is applied there as

$$
p=\frac{\mathrm{d} p}{\mathrm{~d} x}=0
$$

For a thermoelastohydrodynamic lubrication (TEHL) analysis, the initial temperature $\theta_{i}$ is considered to be that of the bulk oil temperature.

\section{METHOD OF SOLUTION}

A simultaneous solution to equations (17), (20), (21) to (23), (29), and (31) is required. For an isothermal analysis, equation (20) is ignored and $\theta=\theta_{i}$ is assumed. In both cases the equations are put into non-dimensional forms to ensure numerical stability. The method of solution is the low relaxation Newton-Raphson method, using Gauss-Seidel iterations described in Jalali-Vahid et al. [25].

The value of pressure at iteration $k$ within a time step is obtained as

$$
p_{i, j}^{k}=p_{i, j}^{k-1}+\Omega \Delta p_{i, j}^{k}
$$

where $\Omega$ is an under-relaxation factor.

In each small step of time, two convergence criteria are required: one for pressures $p_{i, j}$ and the other for the contact load, which should attain the value determined by a previous dynamic analysis, for instance load per ball-to-race contact in a ball bearing. For pressure convergence

$$
\frac{\sum_{i=1}^{n x} \sum_{j=1}^{n y}\left|p_{i, j}^{k}-p_{i, j}^{k-1}\right|}{\sum_{i=1}^{n x} \sum_{j=1}^{n y} p_{i, j}^{k}} \leqslant \varepsilon_{\mathrm{p}}
$$

The error tolerance $\varepsilon_{\mathrm{p}}$ is usually in the range $5 \times$ $10^{-5}-10^{-4}$.

For load convergence, the following criterion is used

$$
\left|W^{*}-\pi\right| \leqslant \varepsilon_{\mathrm{W}}
$$

The error tolerance $\varepsilon_{\mathrm{w}} \approx 10^{-2}$. 
If the criterion in equation (36) is not satisfied, the film thickness is relaxed as

$$
H_{0}^{* k}=H_{0}^{* k-1}+\xi\left|W^{*}-\pi\right|
$$

where $\xi \approx 10^{-7}$ is referred to as a damping factor.

\section{RESULTS AND DISCUSSION}

\subsection{Isothermal analysis}

Grease lubrication studies for high-speed precision applications have not hitherto been reported in open literature. Load and speed parameters from ball bearing dynamics analysis for a high-speed router are used here. However, the analysis method is generic and can be applied to all industrial applications. Figure 2 shows a typical pressure distribution and the corresponding oil film contour. These show typical EHL conditions with the pressure distribution closely following the classical Hertzian pressure distribution, except for the inlet trail due to the wedge and the pressure spike region at the outlet. More instructive information emerges when 2D pressure cuts through the centre of the $3 \mathrm{D}$ distributions are made with the corresponding elastic film shape profiles.

Figure 3 shows these at various loads on a ball in a ball bearing, traversing its orbital path. Figure 3(a) shows how the pressures alter under transient conditions, when a ball proceeds from the low-loaded bearing region to the high-loaded zone. Figure 3(b) shows the plug formed as a part of the overall film thickness, here adhering to the bounding deformed surfaces since no shear is assumed there. The film thickness hardly alters during the ball orbital path, a characteristic insensitivity of EHL films to load.
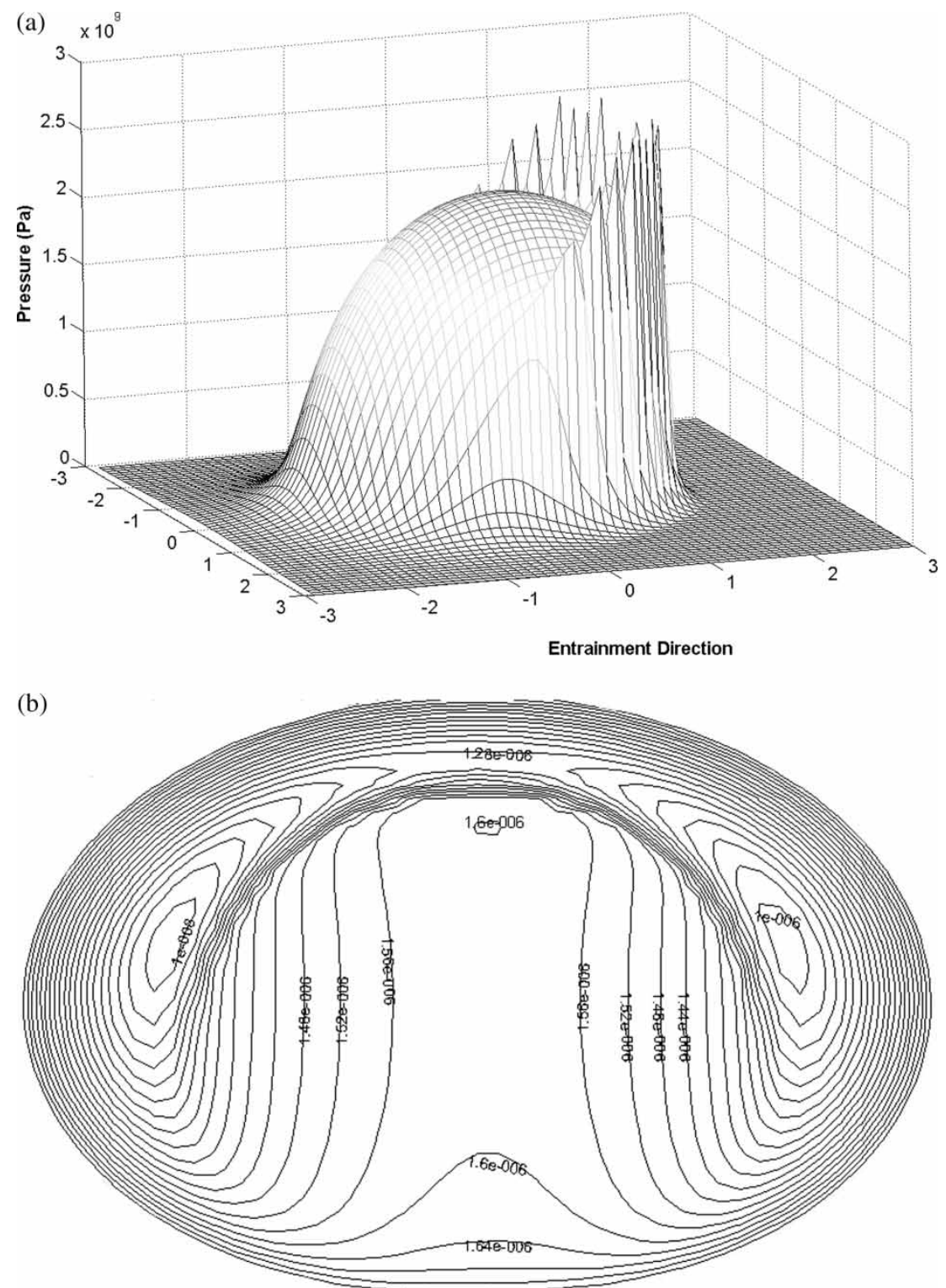

Fig. 2 3D EHL pressure distribution and oil film contour for $W^{*}=2.72 \times 10^{-5}$ 


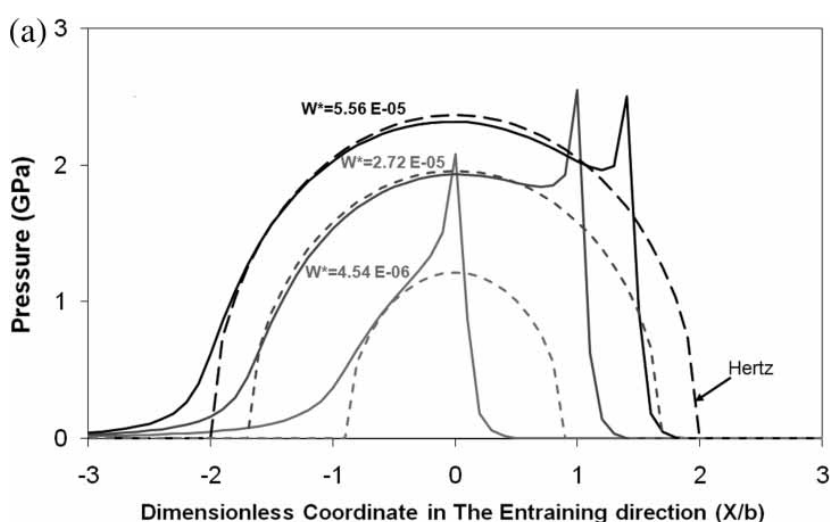

(b)

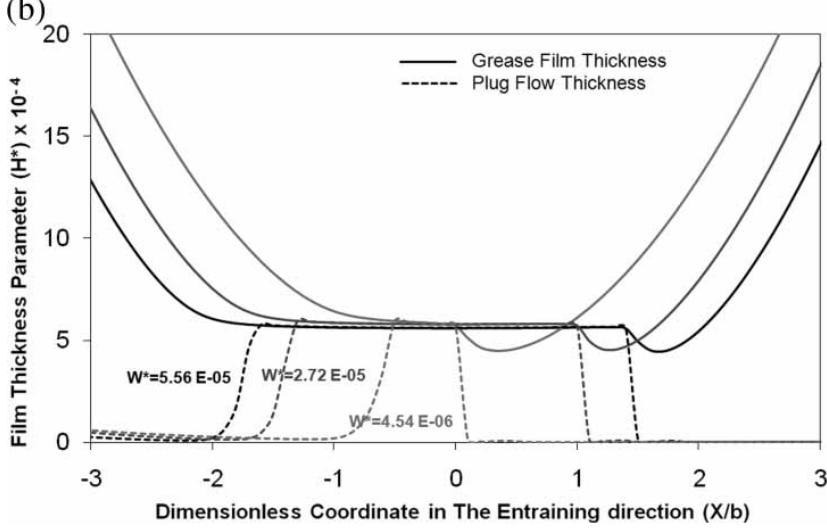

Fig. 3 Pressure distribution and film shape under various loads

Wada et al. [20] show that the grease plug separates from the surface when shearing is assumed there.

The equivalent elastostatic Hertzian pressure distributions for different loads are also shown in Fig. 3(a) with dotted lines. The maximum load parameter acting on a ball is $5.56 \times 10^{-5}$ and the corresponding Hertzian pressure is found to be $2.37 \mathrm{GPa}$.

\subsection{Validation of the numerical model}

It is important to validate the numerical method against experimental measurements. Experimental works for measurement of grease film thickness are only reported at relatively low speeds, for example by Moriuchi et al. [26] using optical interferometry for a steel ball of diameter $38.1 \mathrm{~mm}$ and a surface roughness of $0.02 \mu \mathrm{m} \mathrm{Ra}$. The test grease used was a mineral oil with polyurea with a viscosity of $3.19 \mathrm{~Pa}$ s.

Figure 4 shows the comparison of the current numerical predictions with the experimental findings of Moriuchi et al. [26]. The rolling/sliding velocity for the experiment ranged from 0.1 to $0.6 \mathrm{~m} / \mathrm{s}$, with a load of $16.5 \mathrm{~N}$, giving a maximum Hertzian pressure of $0.65 \mathrm{GPa}$. Furthermore, the experiments were conducted under isothermal conditions (i.e. the temperature of the contact was kept constant at $25^{\circ} \mathrm{C}$ ). Good agreement between the numerical predictions and experimental measurements (grey lines) is noted both for the minimum and central oil film thicknesses.

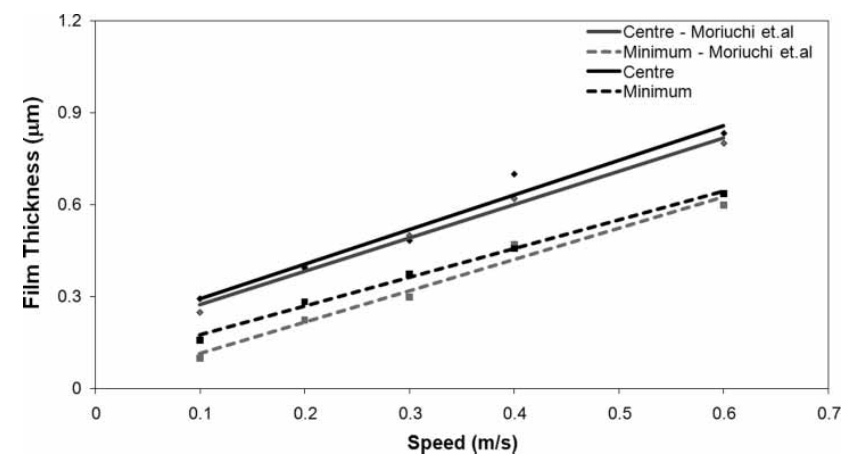

Fig. 4 Comparison of numerical predictions with measurements

\subsection{Grease-to-base oil comparisons}

Grease behaves like discrete spherical soap particles dispersed in the base oil due to its passage through the contact inlet [8] and at higher velocities the viscosity of grease approaches that of the base oil [27]. Figure 5 shows the pressure profile and film thickness for a speed parameter value of $3.68 \times 10^{-9}$ at different values of $W$. A significant feature that differentiates the flow of grease from oil is the existence of the plug flow. In the high-pressure zone it occupies the entire contact area.

Numerical results for pressure distribution for the grease and its base oil in Fig. 5 show very close
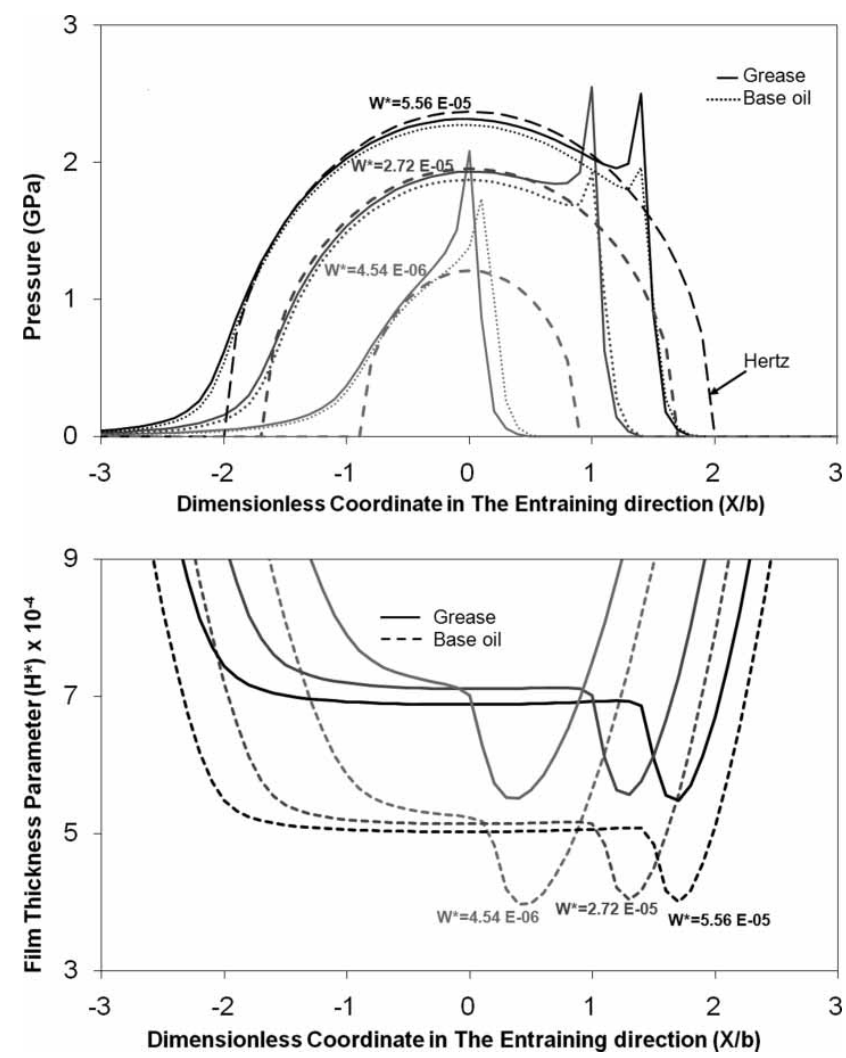

Fig. 5 Pressure profile and film thickness for different load parameters 
agreement, apart from the exit constriction as also shown in reference [17]. The pressure spike tends towards the centre of the contact with grease relative to the base oil alone. In general the pressures are slightly higher for the case of grease. This is in line with the recent findings of Zhang et al. [28] who showed that with the Herschel-Bulkley model as the power index $n$ in equation (5) is increased the EHL pressures rise. This is because the greasy nature of the fluid is enhanced. When the value of $\tau_{0}$ is small, the behaviour of grease tends to Newtonian. Zhang et al. [28] also showed that the position of the maximum pressure (primary peak) did not change with either the power index $n$ or $\tau_{0}$, which is also in line with the current study.

\subsubsection{Effect of speed and load on film thickness}

Fresh (not degraded) greases behave like a solid and at lower speeds form a thick layer almost double that of the degraded grease and base oil [8]. Furthermore, as a rather thick layer, grease does not deform the surfaces, which suggests that fresh grease promotes hydrodynamic regime of lubrication. It is important to ascertain the influence of speed of entraining motion and load on film thickness for a realistic range of operating conditions experienced in industrial applications in rotors and spindles. A significant number of simulations were carried out. Figures 6 to 9 show the comparison of minimum and central film thicknesses for grease and base oil with variation of speed at given contact loads. With degraded grease the film is marginally thicker than the base oil. Physically, this is because the thickener in the form of soap particles builds up a layer on the track during fully flooded conditions [8].

A power relationship between the film thickness and speed parameter for the base oil and grease was found using least square curve fitting. The power relationships for the minimum film thickness are

$$
\begin{aligned}
& H_{\text {base oil }}^{*} \propto U^{* 0.65} \\
& H_{\text {grease }}^{*} \propto U^{* 0.83}
\end{aligned}
$$

For a point contact, the base oil power relation for minimum film thickness with speed suggested by Gohar [29] is 0.7 and by Palacios et al. [30] is 0.74 . The results obtained here are reasonably close to their findings.

The relationship between load and film thickness has been reported in references [1] , [3], [24], [25], [31], and [32]. Figures 10 to 13 show the effect of varying load on elastohydrodynamic film thickness. It is evident that the central film thickness declines with load until proper EHL conditions are encountered where the film thickness becomes virtually independent of load [1-3, 33].

The power relationship for the minimum film thickness parameter and the load parameter is found

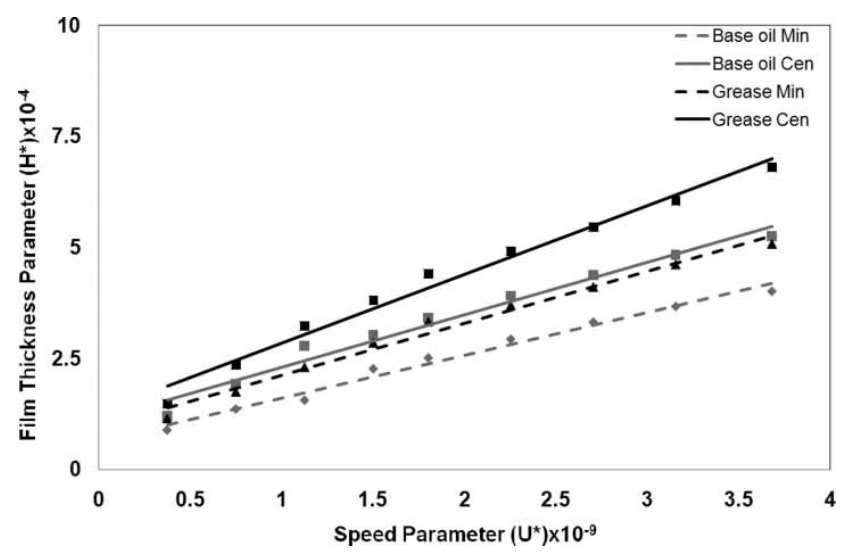

Fig. 6 Film thickness comparison for different speeds with $W^{*}=6.80 \mathrm{E}-06$

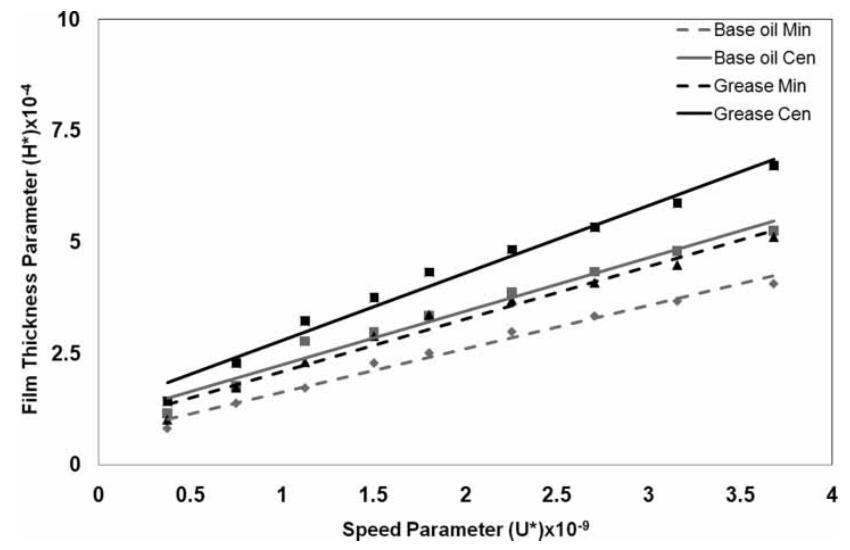

Fig. 7 Film thickness comparison for different speeds at $W^{*}=1.36 \mathrm{E}-05$

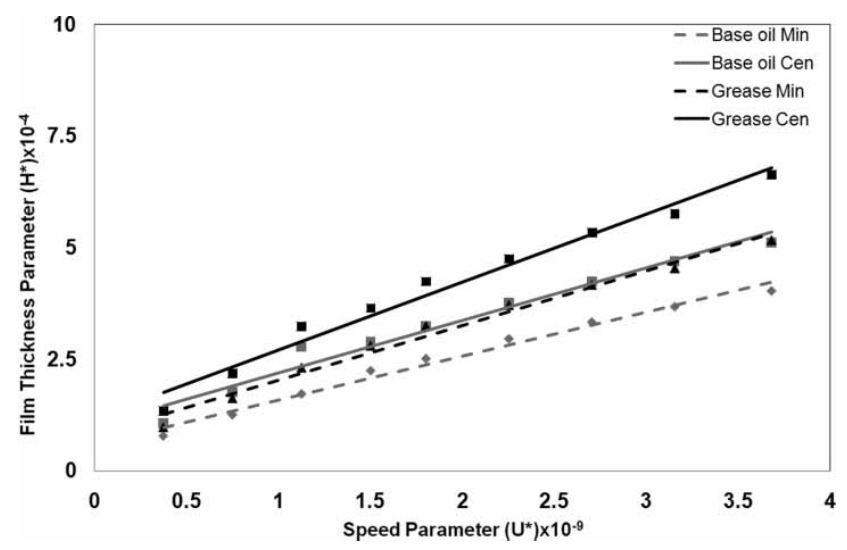

Fig. 8 Film thickness comparison for different speeds at $W^{*}=2.72 \mathrm{E}-05$

using least square curve fitting. The power relation for the base oil for the speed parameters considered in this article is found to be

$$
H_{\text {base oil }}^{*} \propto W^{*-0.056}
$$




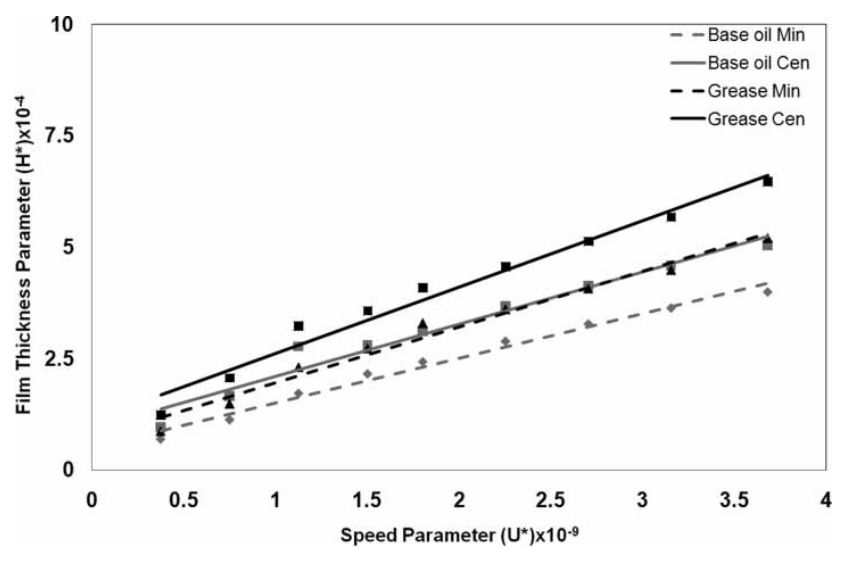

Fig. 9 Film thickness comparison for different speeds at $W^{*}=5.56 \mathrm{E}-05$

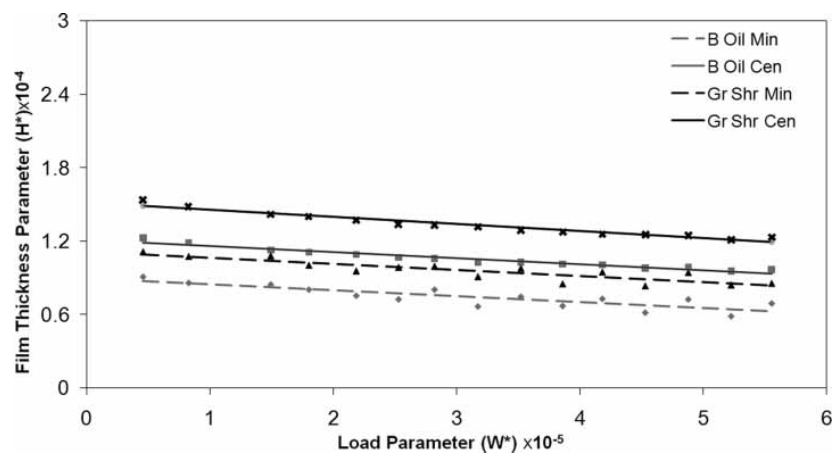

Fig. 10 Film thickness for different loads at $U^{*}=3.75666 \mathrm{E}-10$

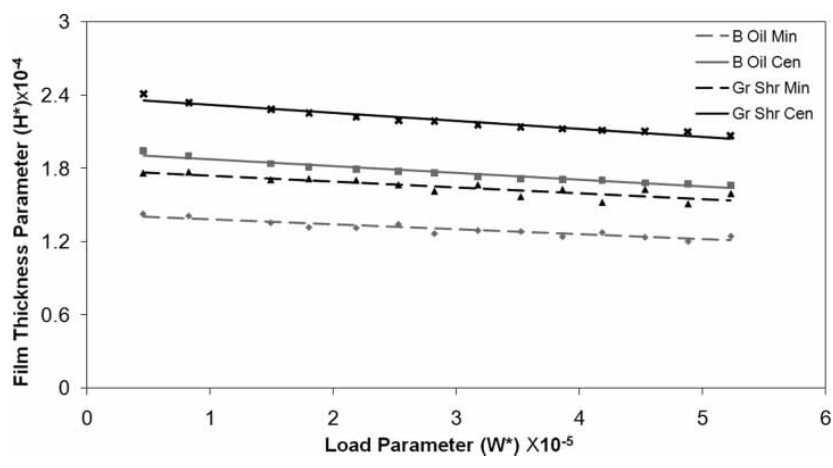

Fig. 11 Film thickness for different loads at $U^{*}=7.51332 \mathrm{E}-10$

The small power index has invariably been reported in the range -0.045 to -0.065 , for example in references [24], [25], and [34] for oil-lubricated EHL point contacts. The same for grease is found to be

$$
H_{\text {grease }}^{*} \propto W^{*-0.068}
$$

For grease lubrication, it was also found that the power index can rise to -0.0808 for high values of $U^{*}>1.8032 \mathrm{E}-09$ (see Fig. 12). The variation of slope from conventional elastohydrodynamic theory may be

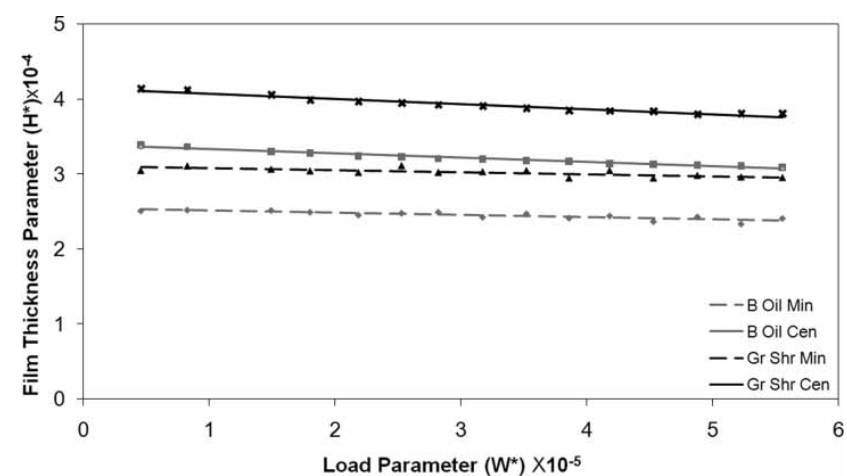

Fig. 12 Film thickness for different loads at $U^{*}=1.8032 \mathrm{E}-09$

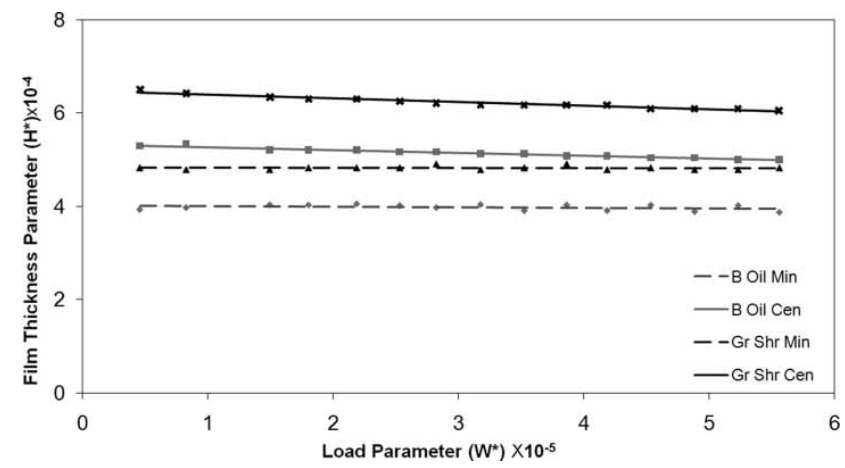

Fig. 13 Film thickness for different loads at $U^{*}=3.68$ 153E-09

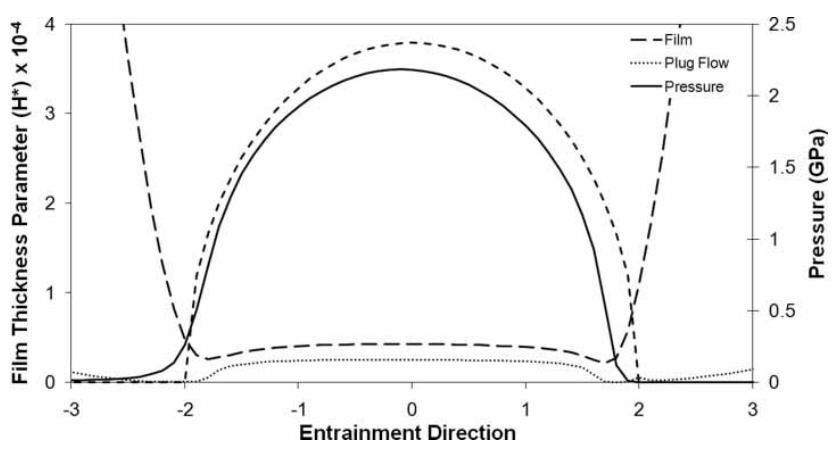

Fig. 14 Pressure profile with $W^{*}=5.56 \mathrm{E}-05$

due to high shear inducing non-Newtonian behaviour. This would need further investigation.

\subsection{Thermal analysis}

The results for grease TEHL analysis are shown in Fig. 14 at the entraining conditions, given by $U^{*}=$ $3.68 \times 10^{-9}$. In the case of point contacts, where pressures developed are quite high, grease behaves like an amorphous solid in a glassy state $[\mathbf{8}]$.

In terms of flow, this suggests that the bulk of the lubricant is transported through the conjunction as a core of solid material with the potential for apparent discontinuities in velocities at the interfaces with the bounding solids, or very thin shear zones, to comply 
with the kinematic conditions. In a section across the film, the lubricant can thus be described as a core in a glassy state, sandwiched between thin shear zones, probably of molecular proportions, in which the difference in velocity of the solidified core relative to the mean entraining velocity is accommodated. This difference between the average velocity of the solidified core and the mean entraining velocity causes a slip as suggested by Ehret et al. [35]. In pure rolling the lubricant core has the common velocity of the two surfaces, with no need for any discontinuity of velocity at either interface. This is only true for the case of oil lubrication, whereas in the case of grease the velocity of the core is different from the moving surfaces (see equation (11)). In sliding, the core of the lubricant could be transported through the conjunction at the entraining velocity, which represents the mean of the two surface speeds. Energy dissipation associated with this and the substantial generation of heat is restricted to the shear zones and it is in these regions that the temperature rise ensures fluid, rather than solid, behaviour. Furthermore, since grease promotes heat transfer through conduction only (see section 2.2), the different thermal properties of the contiguous solids and their kinematic conditions (stationary or moving) lead to different temperature rises in the two layers and different apparent slip velocities. Since a rise in temperature leads to a decrease in the limiting shear stress, such a variation would further decrease the slip in this part of the control volume by the shearthinning effect at the inlet of the conjunction. This will cause the plug flow to disintegrate. Hence, the
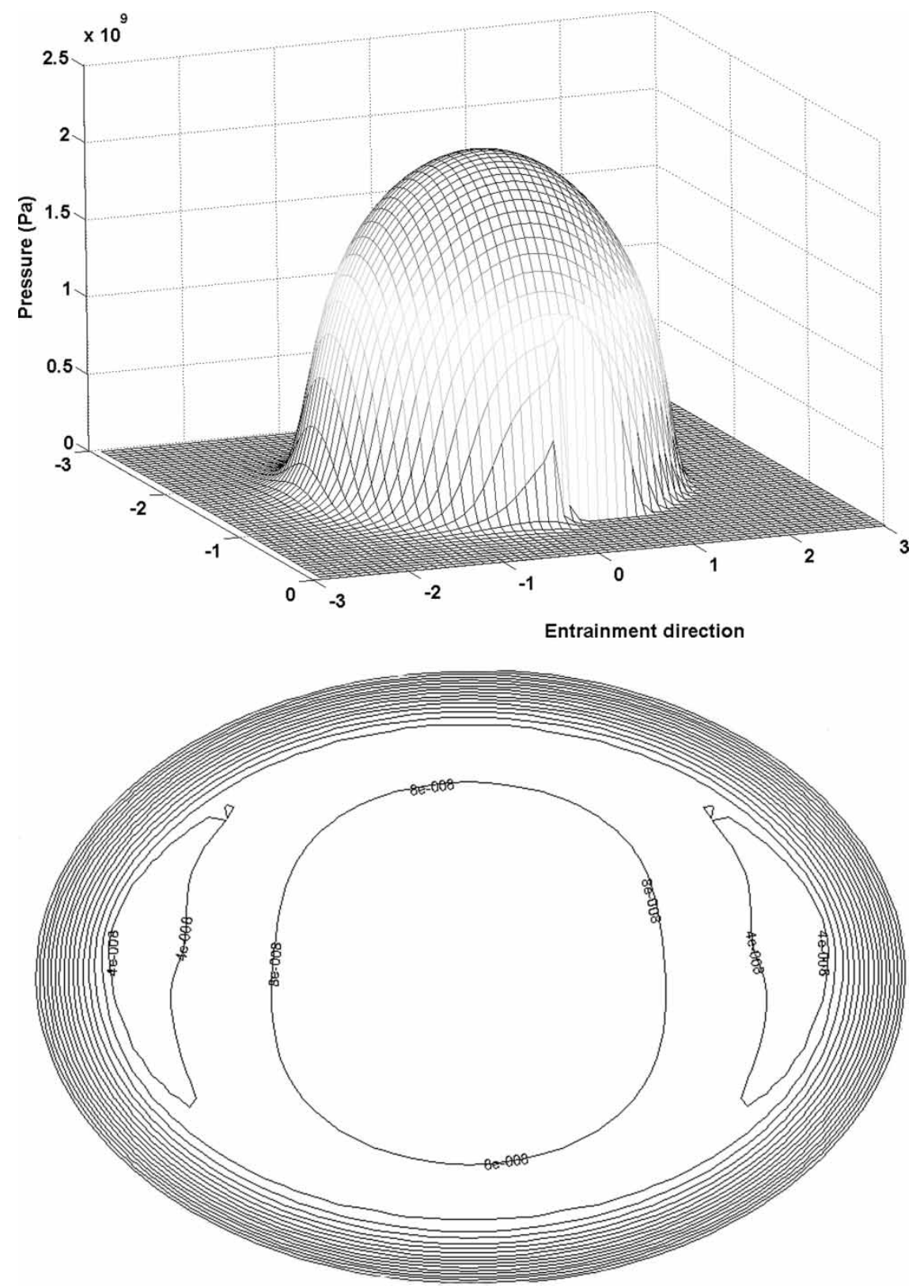

Fig. $153 \mathrm{D}$ pressure distribution and lubricant film contour for $W^{*}=5.56 \mathrm{E}-05$ 

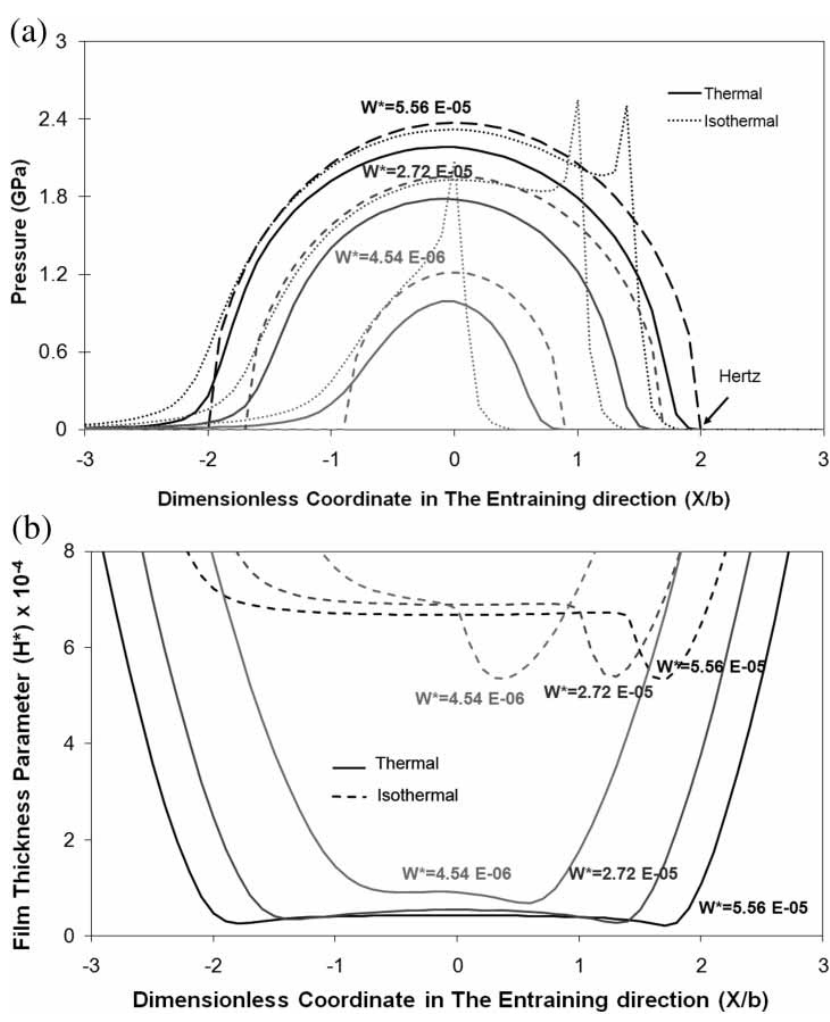

Fig. 16 Thermal and isothermal analyses: (a) TEHL and isothermal pressure distributions and (b) TEHL and isothermal film thickness profiles

plug flow does not occupy the entire contact area as shown in Fig. 14 and layers adjacent to the contacting solids remain liquid. It is also seen that the increase in contact temperature decreases the viscosity of the lubricant by a significant amount. Therefore, in practice in many cases, the shear thinning of grease may result in a change in the regime of lubrication from fluid film to boundary. This problem, together with dominant conductive heat transfer, affecting the dimensional stability of bearing elements, often constitutes the limit for the use of grease-packed bearings (often stated as a spindle speed limitation). The pressure distribution in Fig. 13 is comparable with that in Fig. 5 for isothermal conditions. Note that the reduced viscosity due to a temperature rise has resulted in reducing the film thickness rather dramatically (by an order of magnitude). It has also resulted in starvation of the contact and thus the absence of pressure spike in the vicinity of the exit constriction. In fact, aside from a shortened inlet trail the thermoelastohydrodynamic pressure distribution almost conforms to the Hertzian pressure profile, also shown in the figure.

The lubricant film contour in Fig. 15 shows the disappearance of the usual horseshoe constriction from the outlet region of the contact and to the side constriction, which are typical of starved conditions. The corresponding 3D pressure distribution is also shown with a reduced inlet trail, confirming the same.
Finally, Fig. 16 shows the comparison of pressure distributions and film shapes for thermal and isothermal conditions for different values of $W^{*}$ and with $U^{*}=3.68 \times 10^{-9}$. The same trends of differences between thermal and isothermal conditions are noted.

\section{CONCLUDING REMARKS}

This article provides both isothermal and TEHL analyses of grease-lubricated point contacts. The results show that a plug flow is formed in the conjunction, which in the absence of shear at the contacting surfaces (entraining motion only) fills the entire gap between them. When thermal effects are taken into account the plug is detached from the adjacent surfaces and forms a proportion of the conjunctional film. The remaining film thickness is due to the base oil. These findings are in accord with experimental observations. The predictions of the model also agree very well with previously reported experimental work. Significant thinning of the film of grease due to its thixotropic behaviour and its poor convective cooling can alter the regime of lubrication from fluid film to boundary or mixed, depending on the surface topography. This limits the use of grease in high-speed applications. An example is the high-speed precision routers where spindle speeds of around $40000 \mathrm{r} / \mathrm{min}$ currently represent the limit of grease operational integrity with ceramic-coated bearings, whereas speeds in excess of 50-60 $000 \mathrm{r} / \mathrm{min}$ can be achieved for recirculating oil. When mixed or boundary regimes of lubrication occur, further heat is also generated by asperity interactions. Therefore the model presented here needs further extension to take these into account.

(C) Authors 2010

\section{REFERENCES}

1 Dowson, D. and Higginson, G. R. A numerical solution to the elastohydrodynamic problem. J. Mech. Engng Sci., 1959, 1(1), 6-15.

2 Cameron, A. The principles of lubrication, 1966 (Longman Press, London).

3 Gohar, R. and Rahnejat, H. Fundamentals of tribology, 2008 (Imperial College Press, London).

4 Wedeven, L. D., Evans, D., and Cameron, A. Optical analysis of ball bearing starvation. Trans. ASME, J. Lubr. Technol., 1971, 93, 349.

5 Palacios, J. M., Cameron, A., and Arizmendi, L. Film thickness of grease in rolling contacts. Trans. ASLE, 1981, 24(4), 474-478.

6 Kageyama, H., Machidori, W., and Moriuchi, T. Grease lubrication in elastohydrodynamic contacts. NLGI Spokesman, 1984, 12, 72-81.

7 Muennich, H. C. and Gloeckner, H. J. R. Elastohydrodynamic lubrication of grease lubricated rolling bearings. Trans. ASME, J. Lubr. Technol., 1980, 23, 45. 
8 Cann, P. M., Williamson, B. P., Coy, R. C., and Spikes, H. A. The behaviour of greases in elastohydrodynamic contacts. Appl. Phys. A, 1992, 25, 124-132.

9 Larsson, P. O., Larsson, R., Jolkin, A., and Marklund, O. Pressure fluctuations as grease soaps pass through an EHL contact. Tribol. Int., 2000, 33, 211-216.

10 Poon, S. Y. An experimental study of grease in elastohydrodynamic lubrication, Report CUEDIC-hlechlTR3, Cambridge University Engineering Department, 1969; In abstract, Proc. I. Afeclt. E., 1969-1970, 184 3F, pp. 97-99.

11 Cann, P. M. E. Thin-film grease lubrication. Proc. IMechE, Part J: J. Engineering Tribology, 1999, 213, 405-416.

12 Bauer, W. H., Finkelstein, A. P., and Wiberly, S. E. Flow properties of lithium stearate-oil model greases as functions of soap concentration and temperature. ASLE Trans., 1960, 3, 215-224.

13 Herschel, W. H. and Bulkley, R. Measurement of consistency as applied to rubber-benzene solutions. Proc. ASTM, 1926, 26, 621-633.

14 Bingham, E. C. Fluidity and plasticity, 1922 (McGrawHill, New York).

15 Sisko, A. W. The flow of lubricating greases. Ind. Engng Chem., 1958, 50, 1789-1792.

16 Kauzlarich, J. J. and Greenwood, J. A. Inlet shear heating in elastohydrodynamic lubrication. Trans. ASME, J. Lubr. Technol., 1973, 95, 417-426.

17 Jonkisz, W. and Krzeminski-Freda, $\mathbf{H}$. The properties of elastohydrodynamic grease films. Wear, 1979, 77, 277285.

18 Cheng, J. Elastohydrodynamic grease lubrication theory and numerical solution in line contacts. Tribol. Trans., 1994, 37(4), 711-718.

19 Yoo, J. and Kim, K. Numerical analysis of grease thermal elastohydrodynamic lubrication problems using the Herschel-Bulkley model. Tribol. Int., 1997, 30, 401-408.

20 Wada, S., Hayashi, H., Haga, K, Kawakami, Y., and Okjims, M. Elastohydrodynamic lubrication of a Bingham solid. Bull. JSME, 1977, 20, 110-115.

21 Roelands, C. Correlational aspects of the viscositytemperature-pressure relationship of lubricating oils. PhD Thesis, Delft University, Delft, VRB, Groningen, The Netherlands, 1966.

22 Houpert, L. New results of traction force calculations in elastohydrodynamic contacts. Trans. ASME, J. Tribol., 1985, 107, 241-248.

23 Mansot, J. L., Terech, P., and Martin, J. M. Structural investigation of lubricating greases. Colloids Surf., 1989, 39, 321 .

24 Hamrock, B. J. and Dowson, D. Isothermal elastohydrodynamic lubrication of point contacts. Part I: theoretical formulation. Trans. ASME, J. Lubr. Technol., 1976, 98, 223-229.

25 Jalali-Vahid, D., Rahnejat, H., and Jin, Z. M. Elastohydrodynamic solution for concentrated elliptical point contact of machine elements under combined entraining and squeeze-film motion. Proc. IMechE, Part $J$ : J Engineering Tribology, 2000, 212, 401-411. DOI: $10.1243 / 1350650981542218$.

26 Moriuchi, T., Machidori, W., and Kageyama, H. Grease lubrication in elastohydrodynamic contacts: part II. NLGI Spokesman, 1984, 49(8), 384-386.
27 Sasaki, T., Mori, H., and Okino, N. Theory of grease lubrication of cylindrical roller bearing. Bull. JSME, 1959, 3(10), 212-219.

28 Zhang, J., Khayat, R. E., and Noronha, A. P. Threedimensional lubrication flow of a Herschel-Bulkley fluid. Int. J. Numer. Methods Fluids, 2006, 50, 511-530.

29 Gohar, R. Oil film thickness and rolling friction in elastohydrodynamic point contact. Trans. ASME, J. Lubr. Technol., 1971, 93, 371-382.

30 Palacios, J. M., Cameron, A., and Arizmendi, L. Film thickness of grease in rolling contacts. Trans. ASLE, 1981, 24, 474

31 Cameron, A. and Gohar, R. Theoretical and experimental studies of oil in lubricated point contact. Proc. R. Soc. Lond., 1966, A291, 520-536.

32 Evans, H. P. and Snidle, R. W. Analysis of elastohydrodynamic lubrication of elliptical contacts with rolling along major axis. Proc. IMechE, Part C: J. Mechanical Engineering Science, 1983, 197, 209-211. DOI: 10.1243/PIME_PROC_1983_197_098_02.

33 Johns-Rahnejat, P. M. Pressure and stress distributions under elastohydrodynamic point contacts. $\mathrm{PhD}$ Thesis, Imperial College of Science, Technology and Medicine, University of London, 1988.

34 Rahnejat, H. Influence of vibration on the oil film in concentrated contact. PhD Thesis, Imperial College of Science, Technology and Medicine, University of London, 1984.

35 Ehret, P., Dowson, D., and Taylor, C. M. On lubricant transport conditions in elastohydrodynamic conjunctions. Proc. R. Soc. A, 1998, 454, 763-787.

36 Hunter, R. J. and Frayne, J. Couette flow behaviour of coagulated colloidal suspensions. Colloid Interface Sci., 1979, 71, 30.

\section{APPENDIX 1}

\section{Notation}

$b \quad$ half-width of semi-major axis of

contact ellipse in the $y$-direction

$D \quad$ shear rate

$D_{\mathrm{t}} \quad$ density-temperature

dependency

$\frac{1}{E^{\prime}}=\frac{1}{2}\left(\frac{1-v_{1}^{2}}{E_{1}}+\frac{1-v_{2}^{2}}{E_{2}}\right)$

$h \quad$ film thickness

$h_{0} \quad$ initial film thickness

(undeformed)

$h_{\mathrm{p}} \quad$ plug flow thickness

$H^{*}=\frac{h}{R} \quad$ dimensionless film thickness

$k \quad R \quad$ thermal conductivity of the

lubricant

$n \quad$ Herschel-Bulkley index

$p \quad$ pressure

$p_{\max } \quad$ maximum pressure

$q_{x} \quad$ flowrates in the $x$-direction 


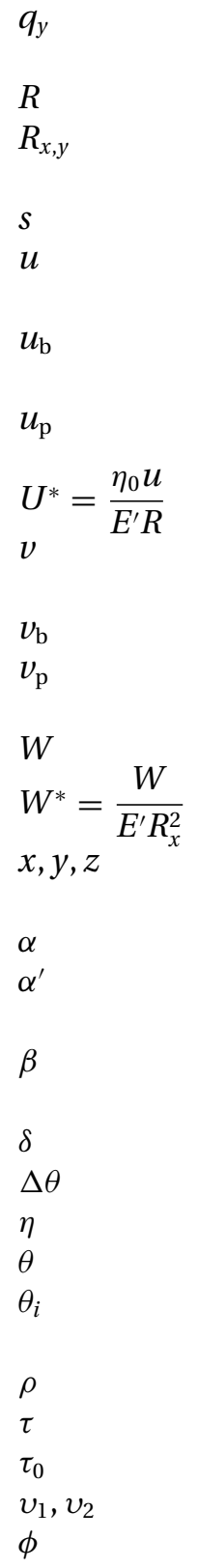

\section{APPENDIX 2}

The rheological properties of grease used in the equation (5) analysis

\begin{tabular}{|c|c|c|}
\hline Parameter & Value & Units \\
\hline Pressure-viscosity index & $z=0.67$ & - \\
\hline $\begin{array}{l}\text { Pressure exponent of } \\
\text { viscosity }\end{array}$ & $\alpha=2.08 \mathrm{e}-8$ & $\mathrm{~Pa}^{-1}$ \\
\hline $\begin{array}{l}\text { Viscosity of lubricant at } \\
\qquad P=0\end{array}$ & $\eta_{\mathrm{bo}}=0.02024$ & Pas \\
\hline $\begin{array}{l}\text { Volume fraction of soap in } \\
\text { oil }\end{array}$ & $\Phi=0.12$ & - \\
\hline $\begin{array}{l}\text { Plastic viscosity of grease } \\
\text { at the contact inlet }\end{array}$ & $\phi_{0}=0.02078$ & - \\
\hline
\end{tabular}

$B \approx 0.25$ is a constant. The value is actually in the range $0.23 \pm 0.02$, which agrees with the Einstein equation for a suspension of non-interacting spheres [36].

\section{APPENDIX 3}

$$
\begin{aligned}
& D_{m, n}=(\bar{y}-\bar{a}) \ln \left[\frac{(\bar{x}-\bar{b})+\sqrt{(\bar{y}-\bar{a})^{2}+(\bar{x}-\bar{b})^{2}}}{(\bar{x}+\bar{b})+\sqrt{(\bar{y}-\bar{a})^{2}+(\bar{x}+\bar{b})^{2}}}\right] \\
&+(\bar{y}+\bar{a}) \ln \left[\frac{(\bar{x}+\bar{b})+\sqrt{(\bar{y}+\bar{a})^{2}+(\bar{x}+\bar{b})^{2}}}{(\bar{x}-\bar{b})+\sqrt{(\bar{y}+\bar{a})^{2}+(\bar{x}-\bar{b})^{2}}}\right] \\
&+(\bar{x}+\bar{b}) \ln \left[\frac{(\bar{y}+\bar{a})+\sqrt{(\bar{y}+\bar{a})^{2}+(\bar{x}+\bar{b})^{2}}}{(\bar{y}-\bar{a})+\sqrt{(\bar{y}-\bar{a})^{2}+(\bar{x}+\bar{b})^{2}}}\right] \\
&+(\bar{x}-\bar{b}) \ln \left[\frac{(\bar{y}-\bar{a})+\sqrt{(\bar{y}-\bar{a})^{2}+(\bar{x}-\bar{b})^{2}}}{(\bar{y}+\bar{a})+\sqrt{(\bar{y}+\bar{a})^{2}+(\bar{x}-\bar{b})^{2}}}\right]
\end{aligned}
$$

Here

$$
\bar{b}=\Delta x / 2, \bar{a}=\Delta y / 2
$$

and note that

$$
\begin{aligned}
& \bar{x}=x_{k, l}-x_{i, j}=m \Delta x \\
& \bar{y}=y_{k, l}-y_{i, j}=n \Delta y
\end{aligned}
$$

Thus

$$
\begin{aligned}
D_{m, n}= & y m \ln \left(\frac{x m+\sqrt{y m^{2}+x m^{2}}}{x p+\sqrt{y m^{2}+x p^{2}}}\right) \\
& +y p \ln \left(\frac{x p+\sqrt{y p^{2}+x p^{2}}}{x m+\sqrt{y p^{2}+x m^{2}}}\right) \\
& +x p \ln \left(\frac{y p+\sqrt{y p^{2}+x p^{2}}}{y m+\sqrt{y m^{2}+x p^{2}}}\right) \\
& +x m \ln \left(\frac{y m+\sqrt{y m^{2}+x m^{2}}}{y p+\sqrt{y p^{2}+x m^{2}}}\right)
\end{aligned}
$$

where $x m=\bar{x}-\bar{b}, x p=\bar{x}+\bar{b}, y m=\bar{y}-\bar{a}$, and $y p=$ $\bar{y}+\bar{a}$. 